\title{
PRODUCTION OF RESISTORS BY ARC PLASMA SPRAYING
}

\author{
R. T. SMYTH and J. C. ANDERSON \\ Materials Section, Department of Electrical Engineering, Imperial College, London SW7 2BT
}

(Received March 12, 1975)

\begin{abstract}
Arc plasma spraying (APS) is an accepted method of producing coatings for many engineering applications. The wide range of materials that can be used to form the thick film coatings make this technique interesting as an alternative method of producing electrical components and circuits.

The manufacturing procedure is outlined and the potential advantages of this method of making thick film resistors are listed.

The effect on the physical and electrical properties of the films produced by variation of the arc plasma gun current, gas flow rate and powder particle size are reported together with the effect of varying gun/substrate distance and the topography of the substrate surface.

It is shown that using a mixture of $\mathrm{NiO}$ and $\mathrm{Fe}_{3} \mathrm{O}_{4}$ powders with a particle size range of $1-20 \mu \mathrm{m}$ it is possible to produce films on a glass substrate with sheet resistivities from 5-500 $\Omega / \mathrm{sq}$; temperature coefficients of resistance vary from +20 to $-8 \times 10^{-4}$ per ${ }^{\circ} \mathrm{C}$, depending on resistor composition and film thickness.

The results given for a 10,000 hour life test carried out at $150^{\circ} \mathrm{C}$ in air show a mean charge in resistance of $\sim-5 \%$.

It is concluded that APS offers a viable method of producing thick film resistors and conductors on low cost substrates.
\end{abstract}

\section{INTRODUCTION}

The application of arc plasma spraying (APS) for the production of coatings with useful electrical properties has been investigated by several workers in recent years ${ }^{1-4}$.

The production of resistors is obviously of prime importance if APS is to become established as an alternative method of producing electrical components or circuits. This paper reports the results that have been obtained in producing mixed oxide thick film resistors.

\section{ARC PLASMA SPRAYING}

In this technique, used for many years in the mechanical engineering industry, a high power dc arc is struck between an annular anode and a rod shaped cathode (Figure 1). A stream of inert gas (argon) blows the arc into the annulus of the anode. This constriction results in the gas flow becoming a high temperature $\left(10,000^{\circ} \mathrm{C}\right)$, high velocity $(60 \mathrm{~m} / \mathrm{sec})$ plasma jet. A fine powder injected into the plasma is melted and accelerated by the jet so that it flows out of the front of the anode as a spray of semi-molten particles. These, on striking a cold substrate, splatcool to form a coating.

The parameters controlling the nature and quality of the coating produced by a given plasma gun are arc current, gas flow rate, powder particle size, nature of the powder material, gun/substrate distance and nature of the substrate surface. All of these parameters have been examined for their relevance to the electrical properties of the deposited film.

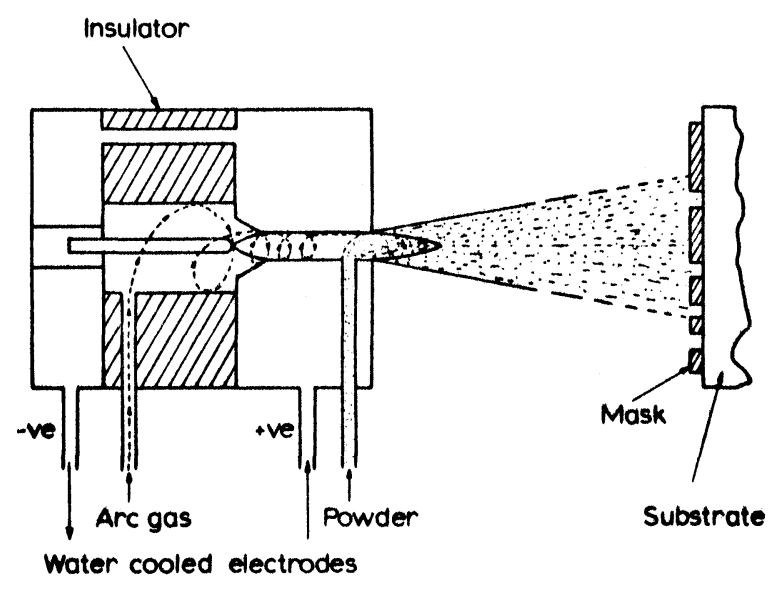

FIGURE 1 APS gun construction. 
The potential advantages of APS as a method of depositing thick film resistors are:

1) Any material with a melting point can be used.

2) The substrate can be kept at low temperature, and usable materials include plastics.

3) The deposited thickness can readily be controlled to quite close limits.

4) There is no practical limitation on the area that can be coated.

5) The system is capable of a high degree of automation.

6) The coatings are robust and resistant to abrasion.

\section{PRODUCTION METHOD}

To produce thick film resistors the substrate is mounted on a holder located in front of the spray gun. The holder is rotated and the gun is traversed laterally, as illustrated in Figure 2. By varying rotation, traverse rate and number of traverses, the thickness of the deposit can be controlled for fixed spraying conditions.

In the present experiments the required coating pattern was defined by covering the slides with a photoresist laminate. This was exposed and developed to leave bare the substrate in the region where deposition was required. After spraying the whole substrate area the remaining photoresist was dissolved leaving the deposit only in the areas exposed by the mask. In the first step a pattern of aluminium conductors was sprayed, and then a second photo-

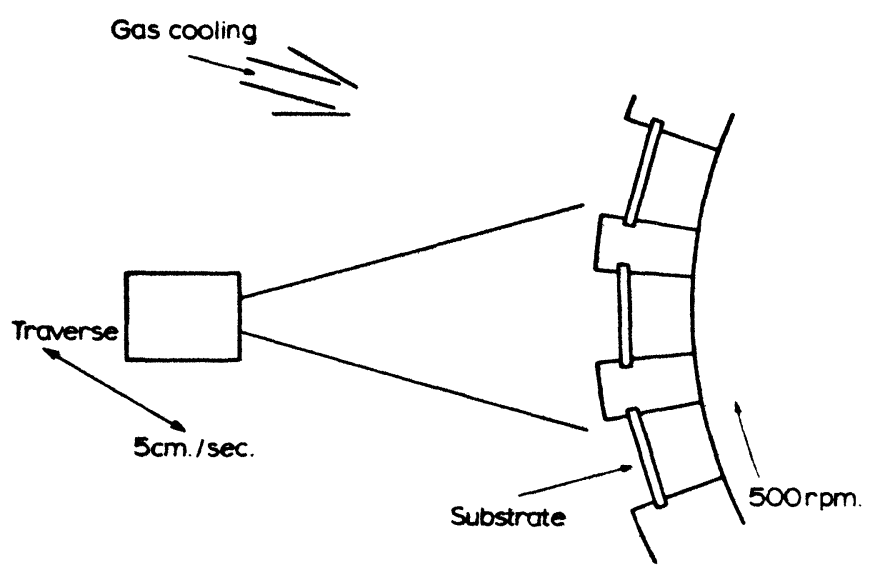

FIGURE 2 APS deposition system. resist step was used to define the resistors. A pattern of standard resistors, each $18 \mathrm{~mm} \times 2.8 \mathrm{~mm}$ was used for most of the work.

In a preliminary investigation ${ }^{4}$ a number of pure and mixed oxide compositions was used. The resistors were assessed by measurement of their temperature coefficient of resistance (TCR) and the mixed oxide composition with the lowest TCR was chosen for the general investigation. This consisted of a $55 \% \mathrm{NiO}$ $45 \% \mathrm{Fe}_{3} \mathrm{O}_{4}$ by weight powder with a particle size $1-20 \mu \mathrm{m}$.

\section{STRUCTURE OF FILMS}

The structure of the films is determined by the build-up of splatted particles. Thus the original particle size is the main factor on which the physical structure depends. The gun parameters of gas flow rate and arc current have little effect on structure over the normal working range but if taken to extremes powdery, non-adherent coating may be produced. Additional factors are substrate roughness and the incident velocity of the particles. In Figure 3 are shown typical scanning micrographs of the films deposited using a nickel oxide powder. Figure 3(a) shows the effect of spraying $1-20 \mu \mathrm{m}$ powder at a gas velocity of mach 0.2 on to a smooth glass substrate and (b) on to a slide grit-blasted to a roughness of $1.3 \mu \mathrm{m}$ CLA. The coating structure appears similar in both cases but a lower magnification examination of the boundary area as in Figure 3(c) reveals a smoother film on the grit blasted substrate. This is due to better adhesion of particles in the initial stages of deposition giving a more uniform surface coverage. This has been confirmed by high speed cine photography which shows that deposited particles are often mobile on the smooth substrate during deposition, leading to coalescence, and a continuous coating is achieved by island growth rather than the build up of individual particles. This variation is only seen during the initial coating stage, no differences being apparent after the initial continuous coating is formed.

The effect of increasing arc gas velocity to mach 0.9 with a corresponding increase in particle velocity is illustrated in Figure 3(d) and (e) which show films prepared at mach 0.2 and 0.9 respectively. The significant feature is the appearance of a number of small spherical particles in the latter. Figure 3(f) shows these at high magnification. They are believed to originate from droplets splashed out from the 


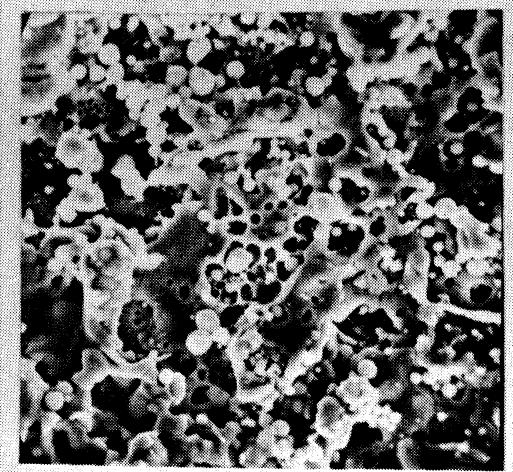

a

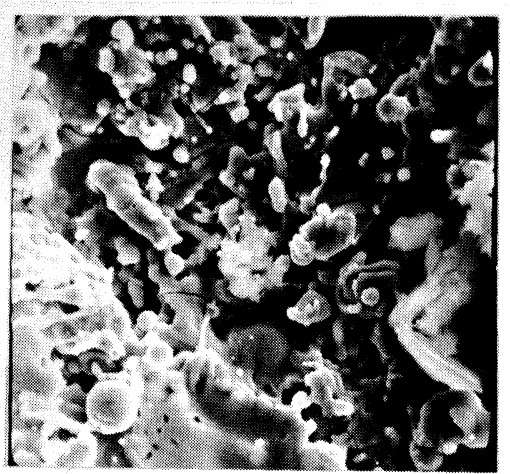

d

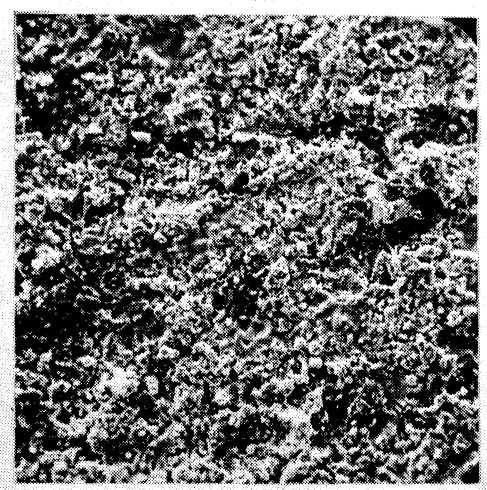

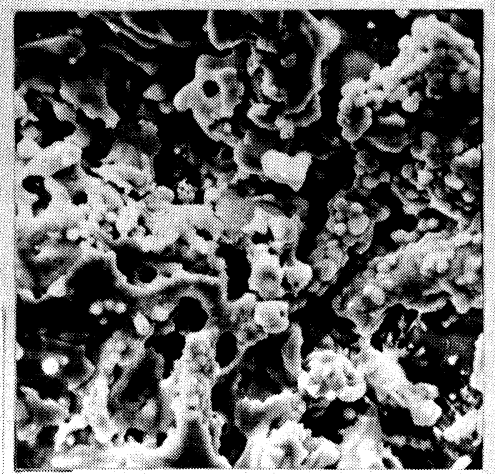

b

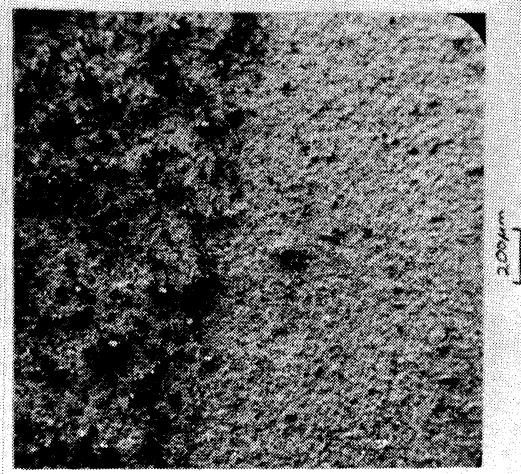

Smooth - $\mid-$ Grit blasted

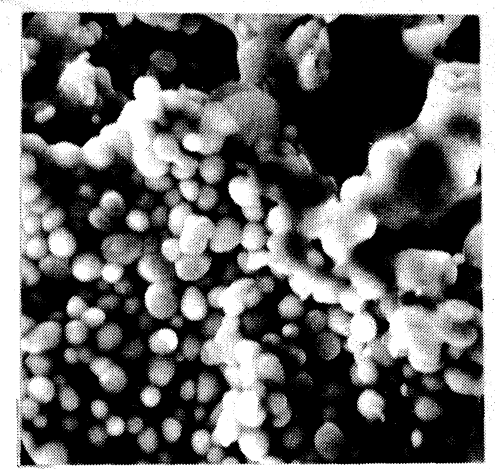

f

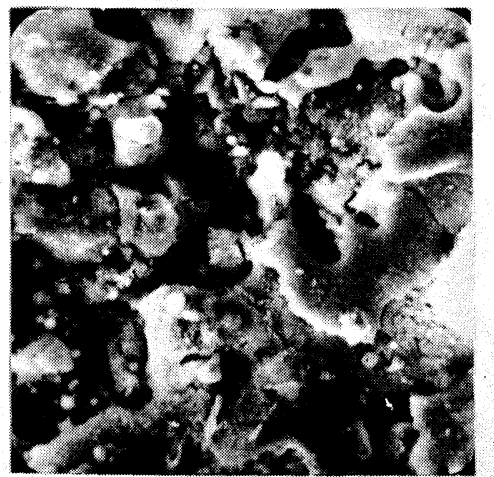

h

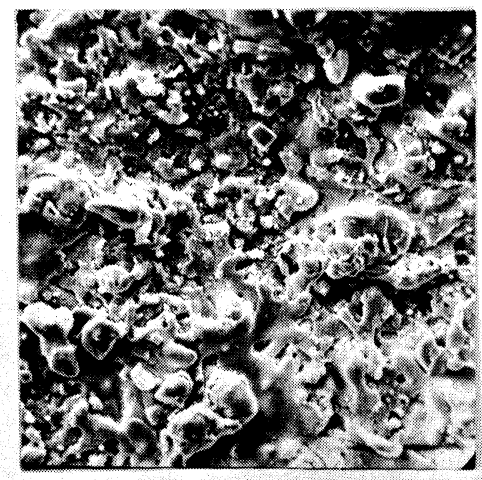

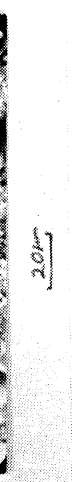


splatted particles, which tend to fill in the interstices between particles giving a denser, smooth film.

The effect of increasing particle size from $1-20 \mu \mathrm{m}$ to $20-40 \mu \mathrm{m}$ is shown in Figure $3(\mathrm{~g})$ and (h) respectively, for mach 0.2 . The splatted particles are obviously much larger with little evidence of the formation of secondary droplets. The large platelets themselves do, however, show signs of fragmentation as seen in Figure 3(i) in which cracks are visible in the larger particles.

\section{ELECTRICAL PROPERTIES}

With fixed spraying conditions of arc current $400 \mathrm{~A}$, argon flow rate $25 \mathrm{l} / \mathrm{min}$ and gun substrate distance
$5 \mathrm{~cm}$ (standard throughout the work) resistors of different sheet resistivity were produced by varying the thickness of deposit. The material used was $50 \%$ $\mathrm{NiO} 50 \% \mathrm{Fe}_{3} \mathrm{O}_{4}$ with particle size in the range $1-20 \mu \mathrm{m}$ and the thickness was varied by varying the number of passes made by the gun. Sheet resistivities from 5 to $500 \Omega /$ sq were produced with the higher values corresponding to thin films which have visible "holes" in them. The coatings are pinhole-free and continuous only for resistivities of $100 \Omega / \mathrm{sq}$ and less. The variation of resistance with film thickness is shown in Figure 4 in which $2 \mu \mathrm{m}$ corresponds to the film thickness at which the film becomes continuous.

The parameters chosen for assessment of the electrical properties at different resistivities were resistance, TCR and third harmonic index (THI). The

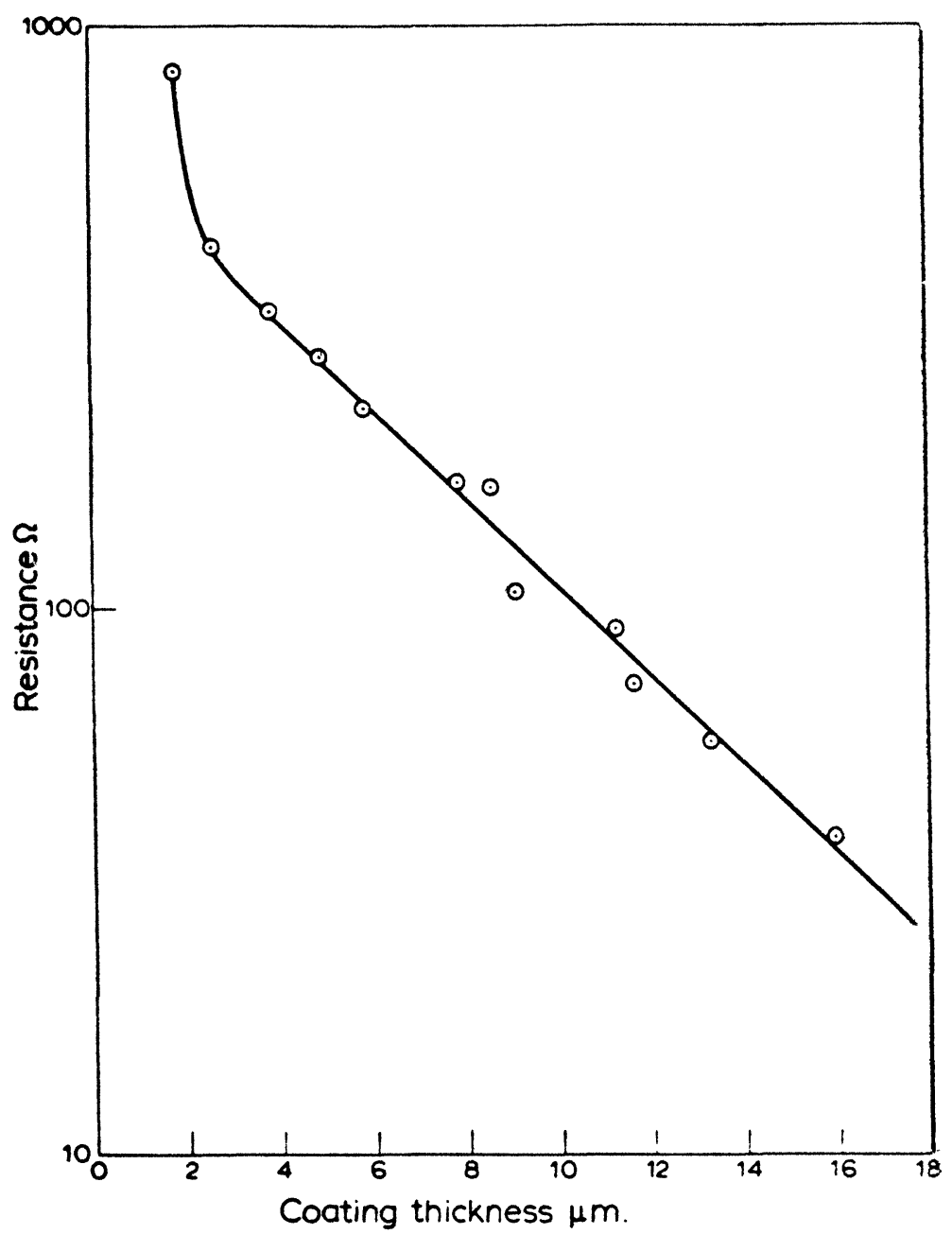

FIGURE 4 Resistance as a function of coating thickness for $1-20 \mu \mathrm{m} 50 / 50 \mathrm{NiO} \mathrm{Fe}_{3} \mathrm{O}_{4}$ powder, current $200 \mathrm{~A}$. flow-rate $25 \mathrm{l} / \mathrm{m}$. 
latter has been defined by Kirby ${ }^{5}$ and shown to be correlated with the electrical noise generated by the resistor. Rysanek and Anderson ${ }^{6}$ have suggested that THI is also a measure of the probable long-term stability of the resistor. It is defined as

$$
\mathrm{THI}=20 \log _{10}\left(\frac{3 \mathrm{rd} \text { harmonic amplitude in } \mu \mathrm{V}}{\text { applied fundamental in volts }}\right)
$$

and can be directly measured by an instrument designed for the purpose (Radiometer, Copenhagen, Model CLT.1).

TCK is defined, in general by $\alpha=\left(1 / \rho_{0}\right) /(\partial \rho / \partial \mathrm{T})$, where $\rho_{0}$ is the resistivity at a reference temperature $\mathrm{T}_{0}$. In this work $\mathrm{T}_{0}$ was $25^{\circ} \mathrm{C}$ and TCR was taken as $\left(1 / R_{0}\right)\left(R-R_{0}\right) /\left(T-T_{0}\right)$, where $R$ was the resistance at $\mathrm{T}^{\circ} \mathrm{C}\left(125^{\circ} \mathrm{C}\right)$.

Using TCR and THI we have investigated the electrical effects of varying the following parameters:

1) Spraying conditions, (a) gun current, (b) argon flow rate, (c) gun/substrate distance

2) Powder composition

3) Particle size

4) Substrate preparation, (a) smooth, (b) grit blasted; 10,000 hour life tests have also been carried out. The experimental results are now given.

\subsection{Effect of Spraying Conditions}

Figure 5 shows THI as a function of gun current and argon flow rate of $\mathrm{NiO}$ resistors having a sheet resistivity of $\sim 2 \Omega / \mathrm{sq}$. It will be seen that the variation is not large, but that the optimum current and flow rate, corresponding to the lowest THI, is around $200 \mathrm{~A}$ with $25 \mathrm{l} / \mathrm{min}$. The effect of substrate roughness was examined at $400 \mathrm{~A}$ and showed a slight lowering of THI for the grit blasted surface. In each case the material is $\mathrm{NiO}$ powder with particle size $1-20 \mu \mathrm{m}$.

Figure 6 shows the effect of flow rate and gun current on the resistivity of the deposited films. Below $30 \mathrm{l} / \mathrm{min}$ the resistivity is found to be fairly independent of flow rate. The use of a grit blasted substrate lowers resistivity for given gun conditions.

In Figure 7 the effect on THI of varying gun/ substrate distance is shown for fixed current and flow-rate. It will be seen that distance has little effect between $50 \mathrm{~mm}$ and $70 \mathrm{~mm}$.

\subsection{Effect of Powder Composition}

The parameters mainly affected by composition are resistivity and TCR. The variation of resistivity with percent by weight of $\mathrm{NiO}$ in an $\mathrm{NiO}-\mathrm{Fe}_{3} \mathrm{O}_{4}$ mixture is shown in Figure 8 for films of equal nominal thickness, whilst the variation of TCR with mean resistance is given in Figure 9 for different compositions and different thicknesses. It will be seen that, although the standard deviation is large, the TCR appears to decrease monotonically with increasing film resistance, i.e. with decreasing thickness. At high values the TCR becomes negative in every case,

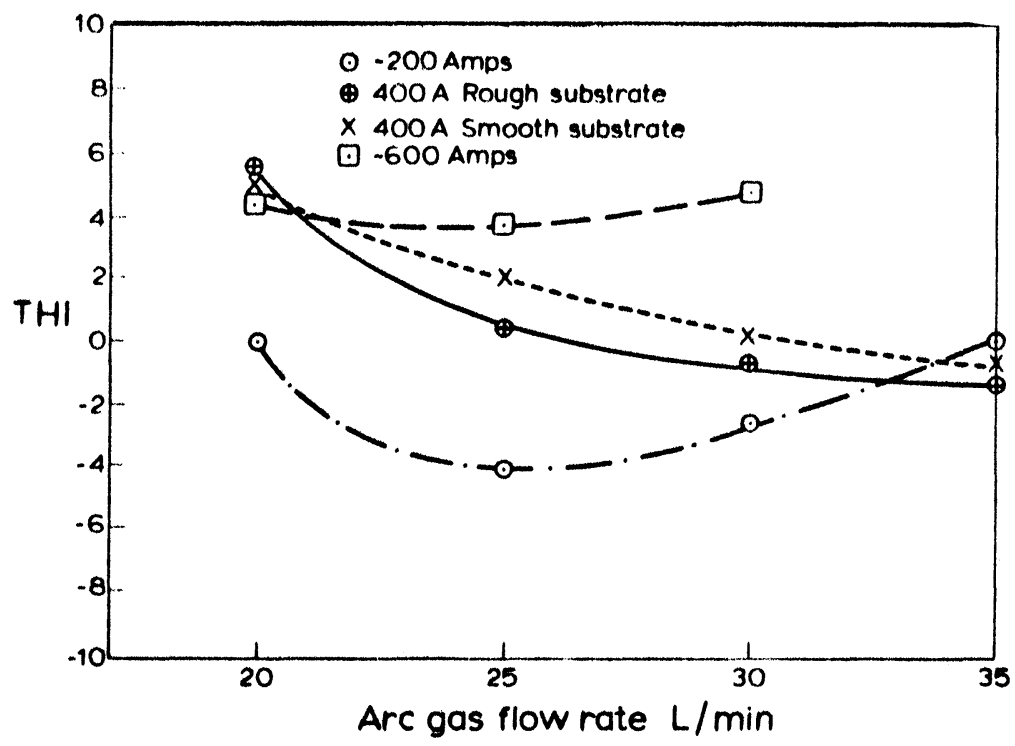

FIGURE 5 THI as a function of flow rate and gun current on smooth and grit-blasted substrates. 1-20 $\mu \mathrm{m} \mathrm{NiO}$ powder, sheet resistivity $\sim 4 \Omega /$ sq. 


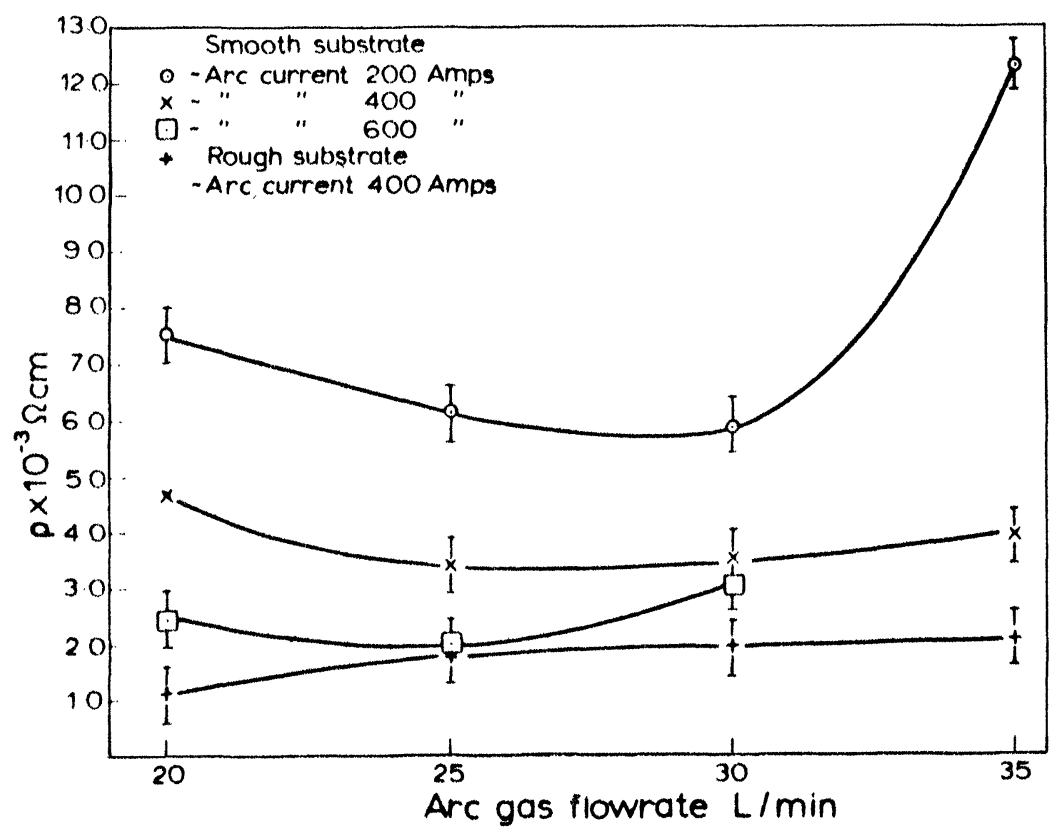

FIGURE 6 Resistivity of sprayed nickel oxide vs plasma arc gas flow rate for various plasma arc power levels.

crossing the axis at higher values for higher $\mathrm{NiO}$ content.

An electron microprobe analysis of a typical film, sprayed from a $56 \% \mathrm{Fe}_{3} \mathrm{O}_{4} 44 \% \mathrm{NiO}$ mixture under standard conditions to a thickness of $\sim 15 \mu \mathrm{m}$ $(\sim 100 \Omega / \mathrm{sq})$, gave an overall iron/nickel ratio of $58.3 / 41.7 \%$, showing that the sticking coefficient of the two powders at the substrate is much the same.

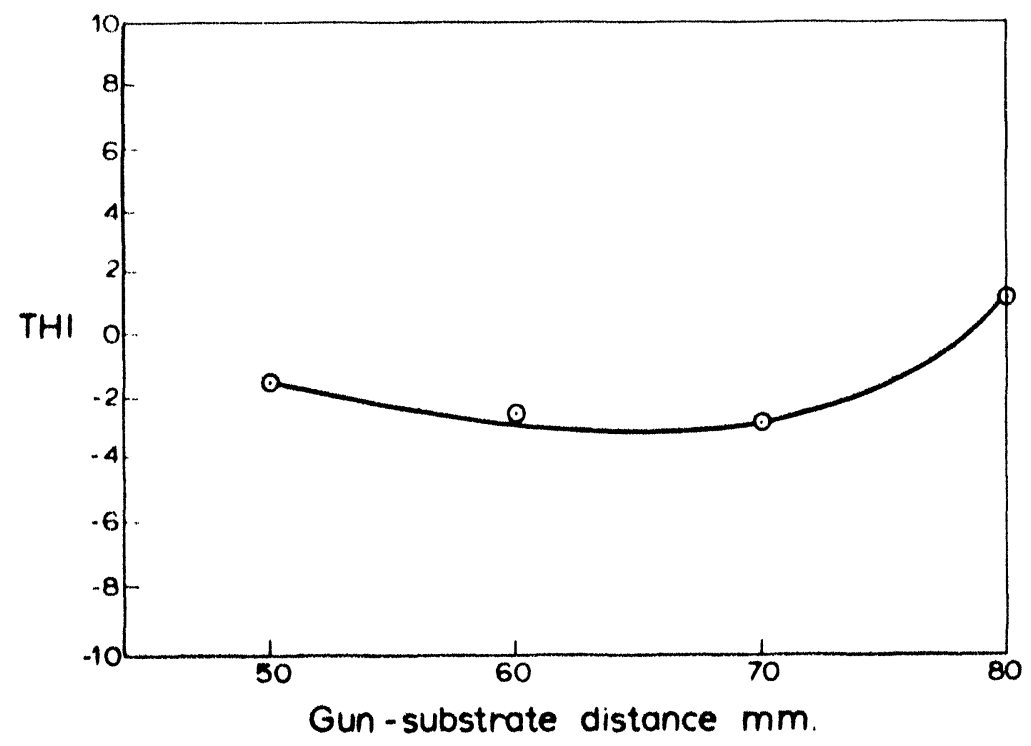

ligURE 7 THI as a function of gun-substrate distance; current $200 \mathrm{~A}$, flow $25 \mathrm{l} / \mathrm{min} ., 1-20 \mu \mathrm{m}, 55 \mathrm{NiO} / 45$ $\mathrm{Fe}_{3} \mathrm{O}_{4}$ powder, smooth substrate. 


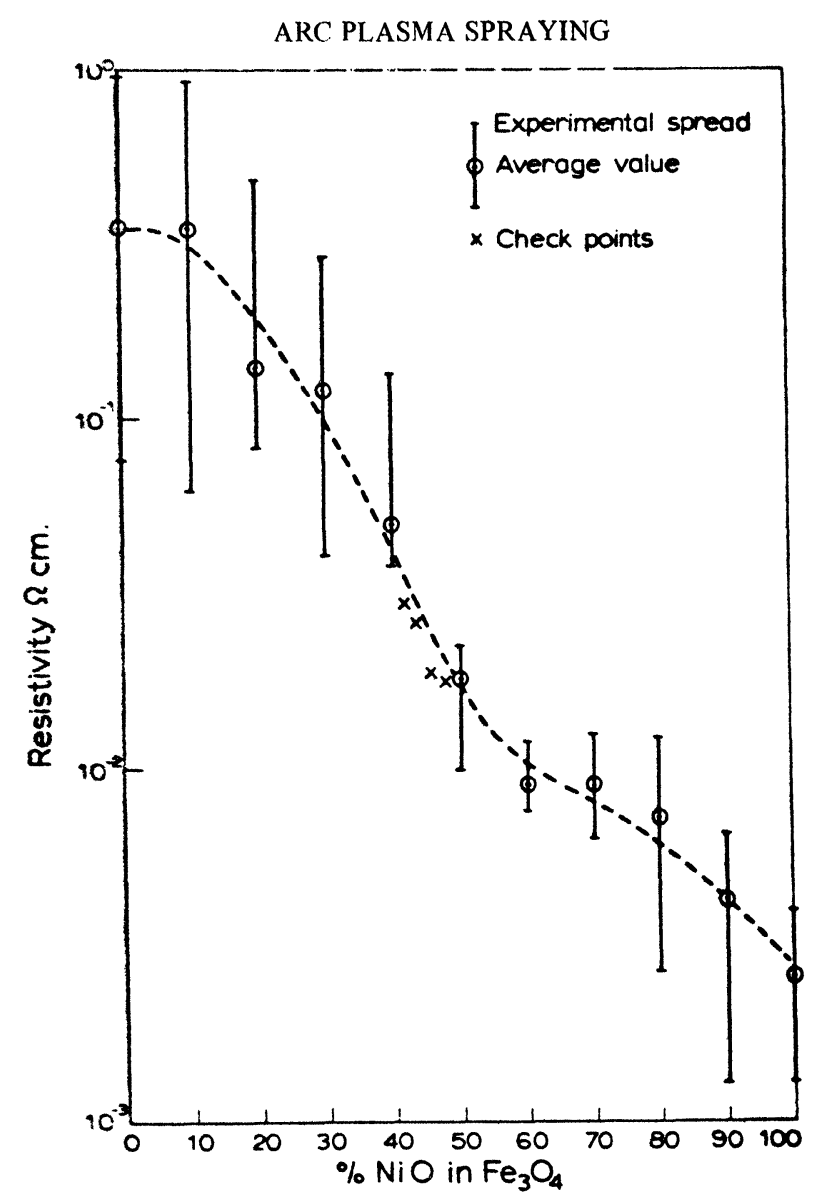

FIGURE 8 Resistivity as a function of composition; 1-20 $\mu \mathrm{m}$ powder, current $200 \mathrm{~A}$, flow $251 / \mathrm{min}$, smooth substrate.

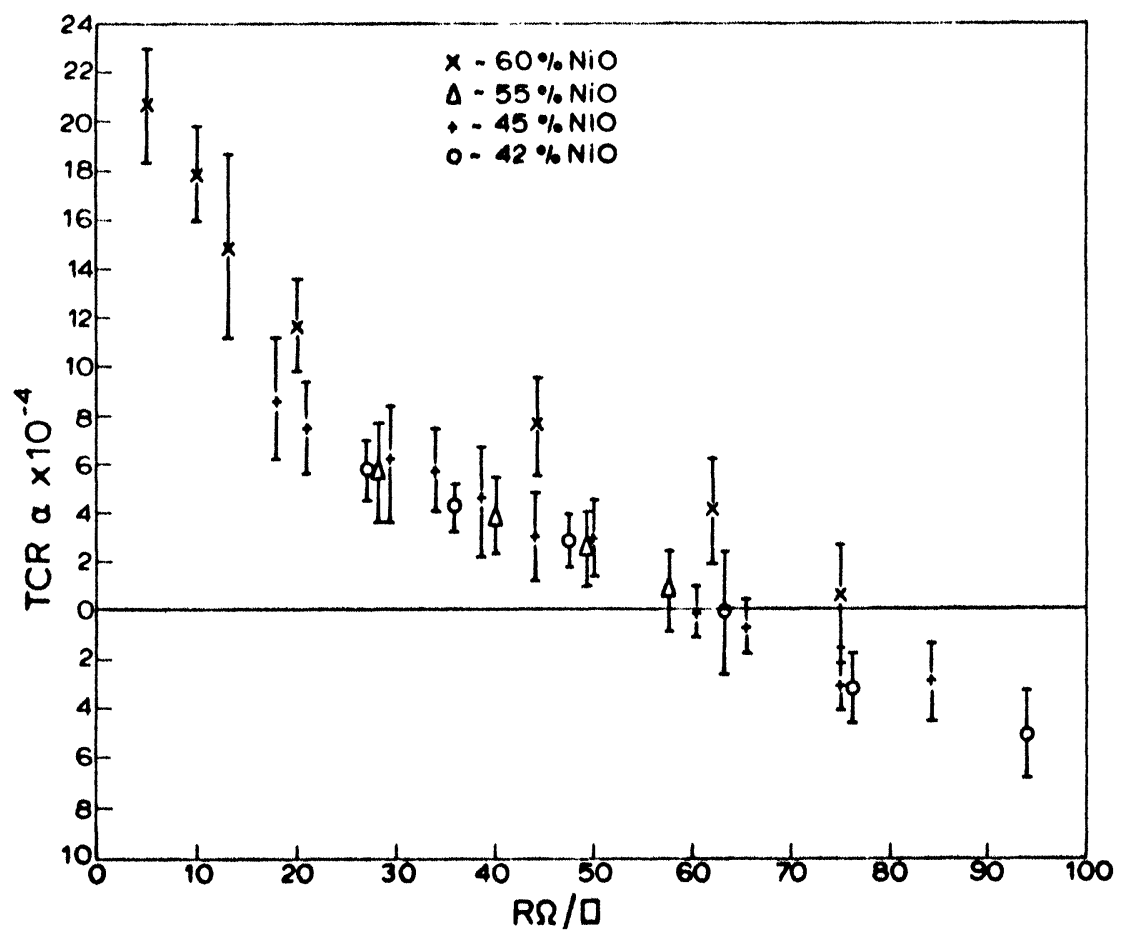

FIGURE 9 TCR as a function of mean sheet resistivity for different compositions $1-20 \mu \mathrm{NiO} / \mathrm{Fe}_{3} \mathrm{O}_{4}$ mixtures; standard spraying conditions, smooth substrate. 
However, individual iron and nickel peaks, appearing together, occasionally show a much higher ratio of $\mathrm{Fe}$ to $\mathrm{Ni}$ and in some cases, using pure $\mathrm{Fe}$ and $\mathrm{Ni}$ to calibrate the peaks, it would appear that free iron is present in some groups of particles. Despite this, however, sprayed $\mathrm{Fe}_{3} \mathrm{O}_{4}$ films show a resistivity of $\sim 10^{-1} \Omega / \mathrm{cm}$, whilst bulk material has a value of $\sim 10^{-2} \Omega / \mathrm{cm}$. No free nickel particles were detected.

Borgianni et al. ${ }^{7}$ have shown that there is some loss of oxygen from $\mathrm{NiO}$ on spraying; these results show that this also occurs with $\mathrm{Fe}_{3} \mathrm{O}_{4}$. It is not possible to make accurate measurements of the bulk resistivity of sprayed material because of the influence of the film structure on measured resistance. However, we may conclude that sprayed $\mathrm{NiO}$ has a lower resistivity than sprayed $\mathrm{Fe}_{3} \mathrm{O}_{4}$ and that, for a given thickness of film, increasing the $\mathrm{Fe}_{3} \mathrm{O}_{4}$ percentage pushes the TCR in the negative direction.

\subsection{Effect of Particle Size}

In the previous section (Figure $3(\mathrm{~g})$ and $(\mathrm{h})$ ) are shown scanning micrographs of deposits with $\mathrm{NiO}$ particles of different sizes prepared with gun conditions of $200 \mathrm{~A}$ and $251 / \mathrm{cm}$. Figure 10 shows THI and surface roughness for the same films. It is reasonable to suppose that the third harmonic component arises from non-linearity associated with grain boundaries between splatted particles. There will be a localized strain and disorder at these boundaries which may give rise to localized charge and hence to a non-linear current-voltage relationship across the boundary. In such a case it would be expected that THI will increase with decreasing particle size, i.e. with increase in the number of boundaries. Figure 10 shows that this effect is small.

In Figure 11 is shown the variation in resistivity with particle size for $\mathrm{NiO}$ films, with smooth substrates, produced with the same number of gun passes and fixed spraying conditions. The increase in resistivity for the larger particles is due to the increasing porosity of the film as particle size increases. The rise in resistivity at very low particle sizes may be associated with the particles losing heat so that they do not easily bond to each other on arrival at the substrate.

\subsection{Effect of Substrate Preparation}

(a) Grit blasting The principal effect of grit blasting is to increase the number of particles adhering to the substrate in the initial stages of deposition. This is evidenced by the micrographs of Figure 3(a), (b) and (c). The effects on electrical properties are consistent with this model and are shown in Figures 5 and 6. In the case of THI there is

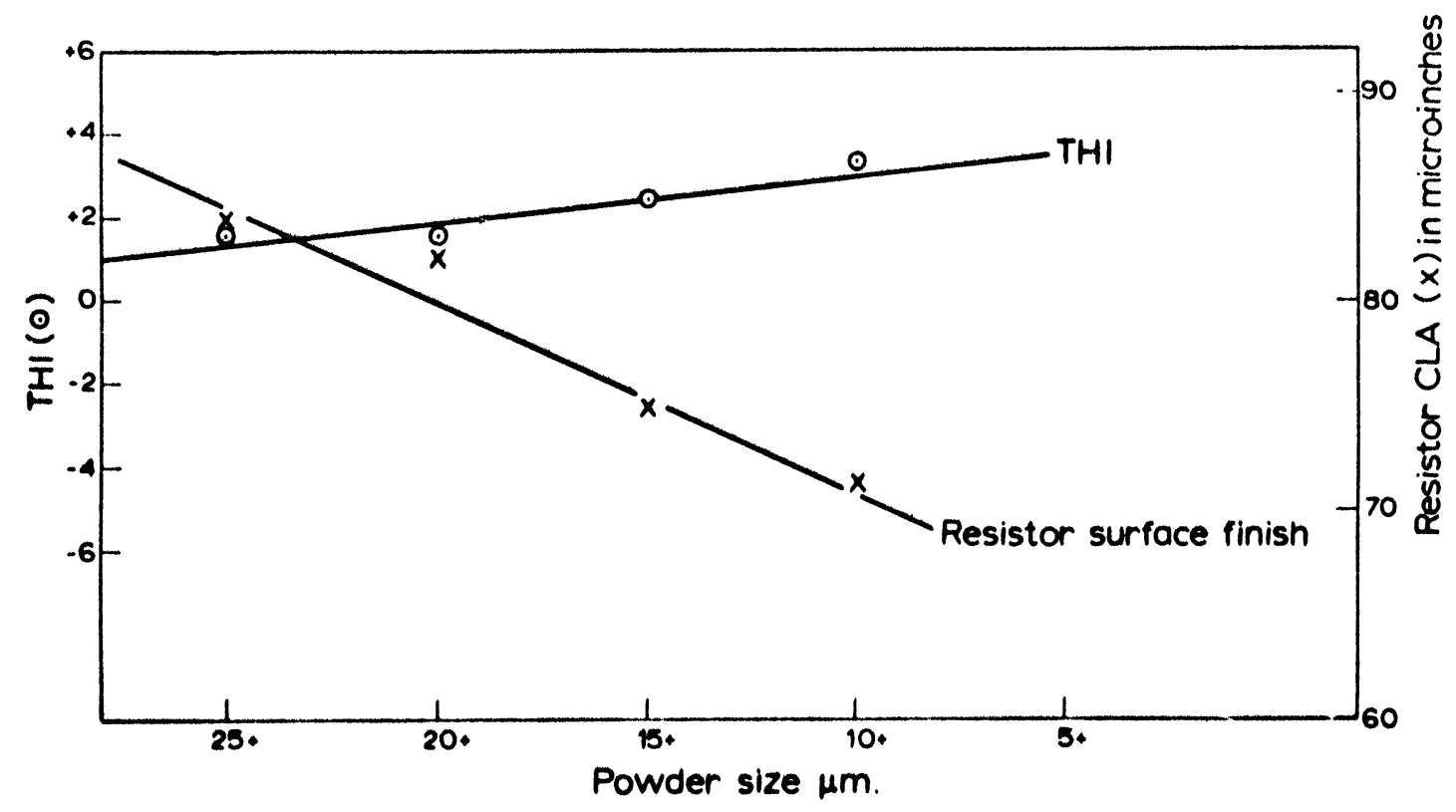

FIGURE 10 THI and surface roughness (CLA) as a function of particle size; NiO powder, $200 \mathrm{~A}, 25 \mathrm{l} / \mathrm{min}$, smooth substrate. For each particle size all smaller particles are included. 


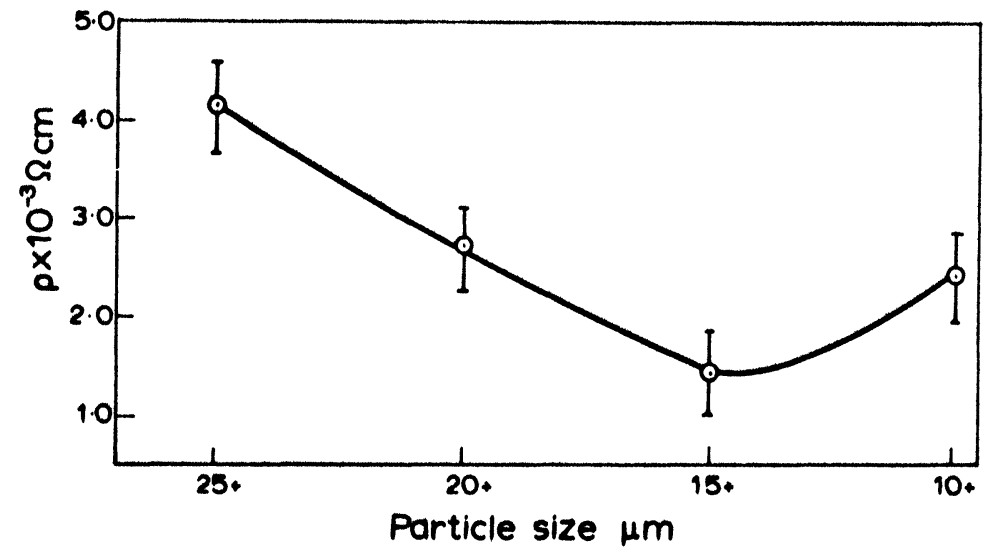

FIGURE 11 Resistivity as a function of particle size for the films of Figure 10.

a slight lowering of its value, due to denser packing of the particles, and the resistivity for a given thickness is lowered for the same reason.

(b) Heating Films were deposited with the substrates heated to $200^{\circ} \mathrm{C}$. No significant improvement in properties on either smooth or grit-blasted substrates was observed.

\subsection{Life Tests}

The results of 10,000 hour life tests carried out at $150^{\circ} \mathrm{C}$ in air, are shown as histograms of fractional change in resistance, $\Delta R / R$, in Figures 12 and 13 .
These are, respectively, for $55 / 45 \mathrm{NiO}-\mathrm{Fe}_{3} \mathrm{O}_{4}$ resistors of $85 \Omega$ and $340 \Omega$ prepared under standard conditions with powder particle size in the range $1-20 \mu$ and smooth substrates. It will be seen that the change in resistance is always less than $\pm 12 \%$ with a mean of $\sim-5 \%$ for most resistors; in fact, they are remarkably stable. Each histogram refers to the mean values for $160-180$ resistors.

\subsection{Reproducibility}

In Figure 14 is shown the standard deviation in resistivity for different batches of resistors having particular mean values, each batch being deposited in

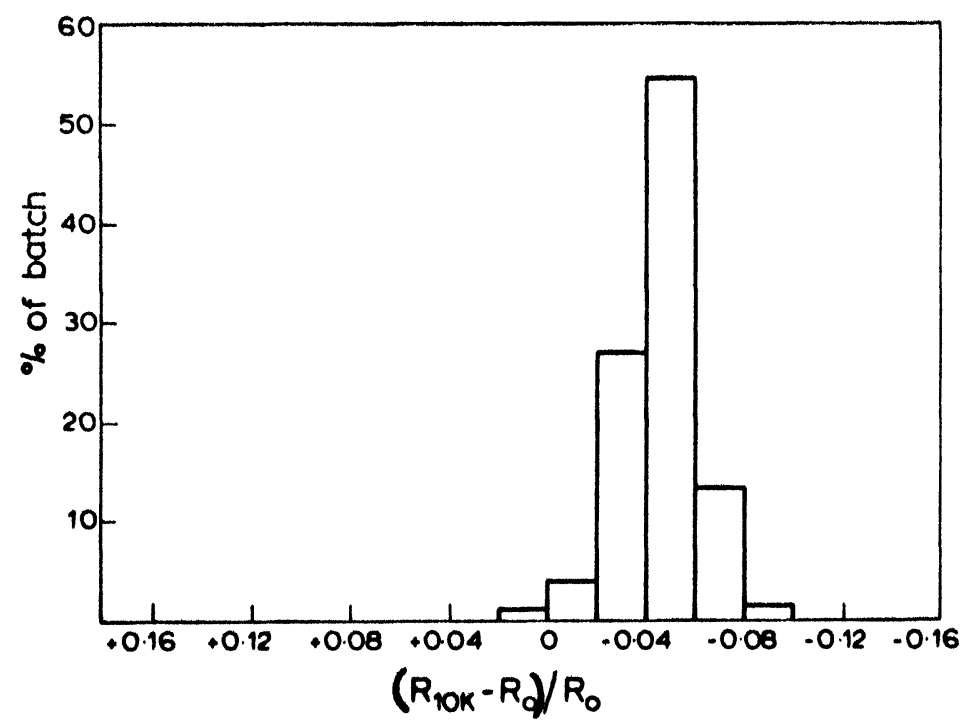

FIGURE 1210,000 hour life test for $85 \Omega$ resistors; $1-20 \mu \mathrm{m}, 55 \mathrm{NiO} / 45 \mathrm{Fe}_{3} \mathrm{O}_{4}$ powder, $200 \mathrm{~A}, 25 \mathrm{l} / \mathrm{m}$, smooth substrates, where $R_{10 \mathrm{~K}}$ is the resistance after 10,000 hours. 


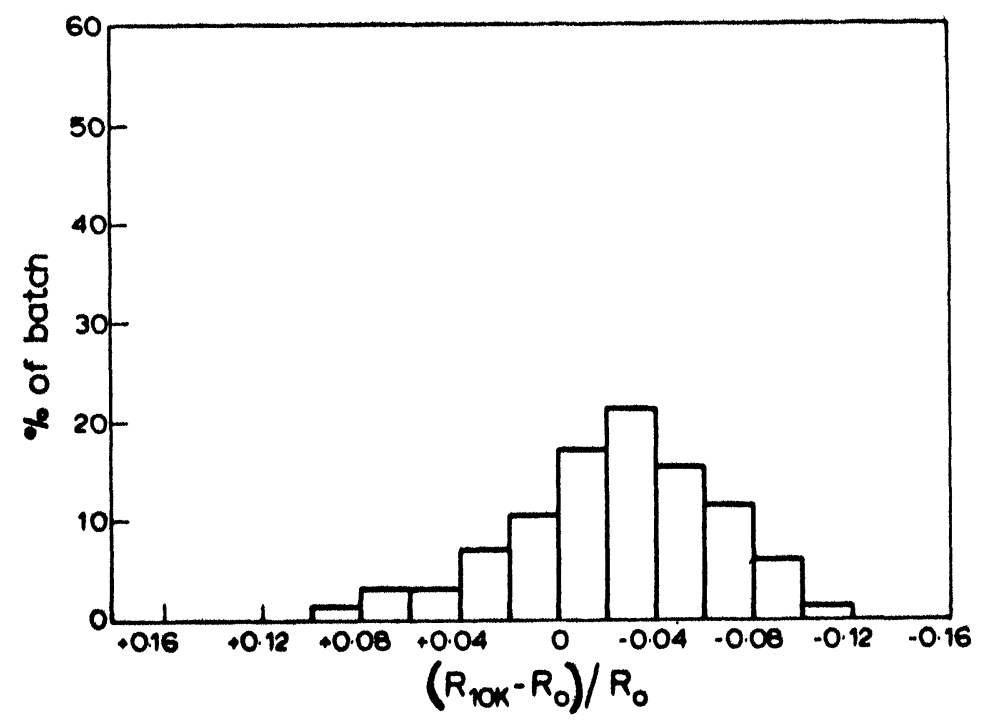

FIGURE $13 \quad 10,000$ hour life test for $340 \Omega$ resistors, conditions as in Figure 12.

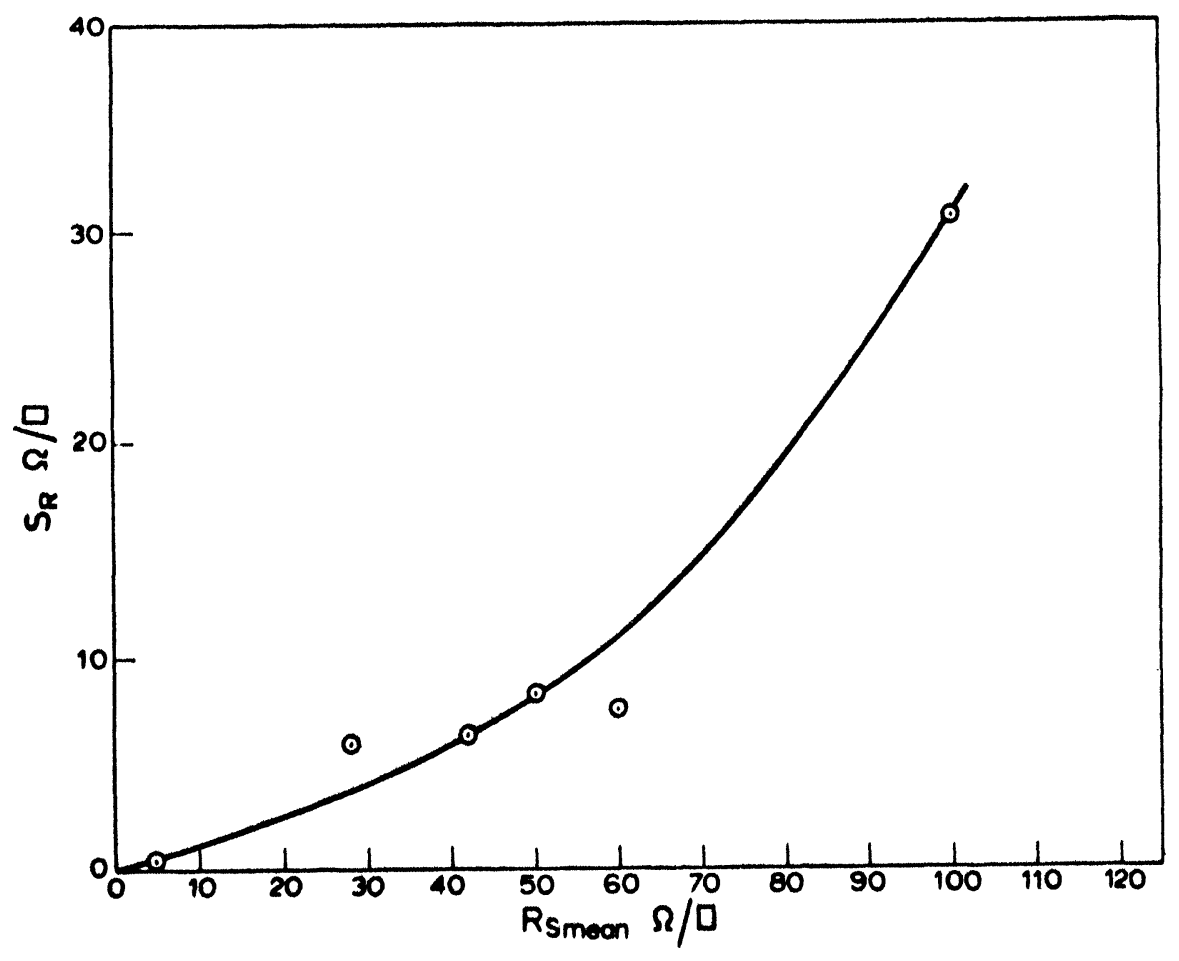

FIGURE 14 Standard deviation in resistance value as a function of mean resistance for $1-20 \mu \mathrm{m}, 55 \mathrm{NiO} / 45$ $\mathrm{Fe}_{3} \mathrm{O}_{4}$ powder, $200 \mathrm{~A}, 25 \mathrm{l} / \mathrm{m}$, where $\mathrm{R}_{\mathrm{S}}$ mean is the mean sheet resistance. 
a single production run. The resistors were prepared from $55 / 45 \mathrm{NiO}-\mathrm{Fe}_{3} \mathrm{O}_{4}$ powder of particle size 1-20 $\mu$ with standard gun conditions. The substrates were grit blasted and the mean resistance was varied by changing the number of spraying passes made by the gun.

\section{DISCUSSION AND CONCLUSIONS}

The properties of APS resistors can be understood in terms of the mechanics of the deposition process. The films are necessarily particulate in structure and include many grain boundaries and defects. For this reason their THI values do not compare favourably with screen-printed and fired thick film resistors, or cracked carbon film resistors. With relatively crude control equipment, as used in this work, it is possible to produce $95 \%$ of resistors within $\pm 20 \%$ tolerance in a single run. Whilst cheap glass substrates have been used in the present project, plastic or laminate substrates can be used, and resistors have even been successfully sprayed on paper. The deposition process is fast and the photoresist masking system allows complex patterns to be readily produced. The resolution is summarized, for the present work, as

Minimum width of conducting path

$50 \mu \mathrm{m}$

Minimum separation for parallel paths

$80 \mu \mathrm{m}$

Coating thickness range

$5-60 \mu \mathrm{m}$

Minimum surface finish

$1.5 \mu \mathrm{m}$ C.L.A.

The materials used are cheap and the resistors show satisfactory long-term stability.

It is concluded that APS offers a technology for cheap quantity production of resistors and conduc- tors on low-cost substrates. Standard trimming techniques, now in use with screen-printed thick films, could be employed to upgrade tolerances but the system also offers the advantage that resistance can be monitored during deposition, so that production to close tolerance specifications using automatic control of gun traverses is relatively straightforward.

\section{ACKNOWLEDGEMENTS}

The assistance of the Science Research Council, in the form of a research grant, is acknowledged with gratitude.

\section{REFERENCES}

1. T. L. Mackay and A. N. Muller, "Plasma sprayed dielectric coatings for heat sinks in electronic packaging" $\mathrm{Am}$. Ceram. Soc. Bull., 46, 833 (1967).

2. D. H. Harris and R. J. Janowiecki, "Arc plasma deposits may yield some big microwave dividends", Electronics, 43, 108 (1970).

3. M. Braguier J. Béjat, R. Tueta, M. Verna, G. Aubin and C. Naturel, "Improvements of plasma spraying processes for hybrid microelectronics", Proc. Conf. on Hybrid Microelectronics, Kent 1973, (I.E.R.E., London 1973) p. 15.

4. J. C. Anderson, R. T. Smyth and E. J. Weidmann, "Third harmonic index measurements on printed and sprayed thick films", Proc. Conf. on Hybrid Microelectronics, Kent 1973 (I.E.R.E. London 1973) p. 251.

5. P. L. Kirby, "The non-linearity of fixed resistors", Electron. Engineering, 37, 722 (1965).

6. J.C. Anderson and V. Rysanek, "Prediction of the stability of thin film resistors", Radio and Electron. Eng., 39, 321 (1970).

7. C. Borgianni, M. Capitelli, F. Cramarossa, L. Triolo and E. Molinari, "The behaviour of metal oxides injected into an argon induction plasma", Combust. and Flame, 13, 181 (1969). 

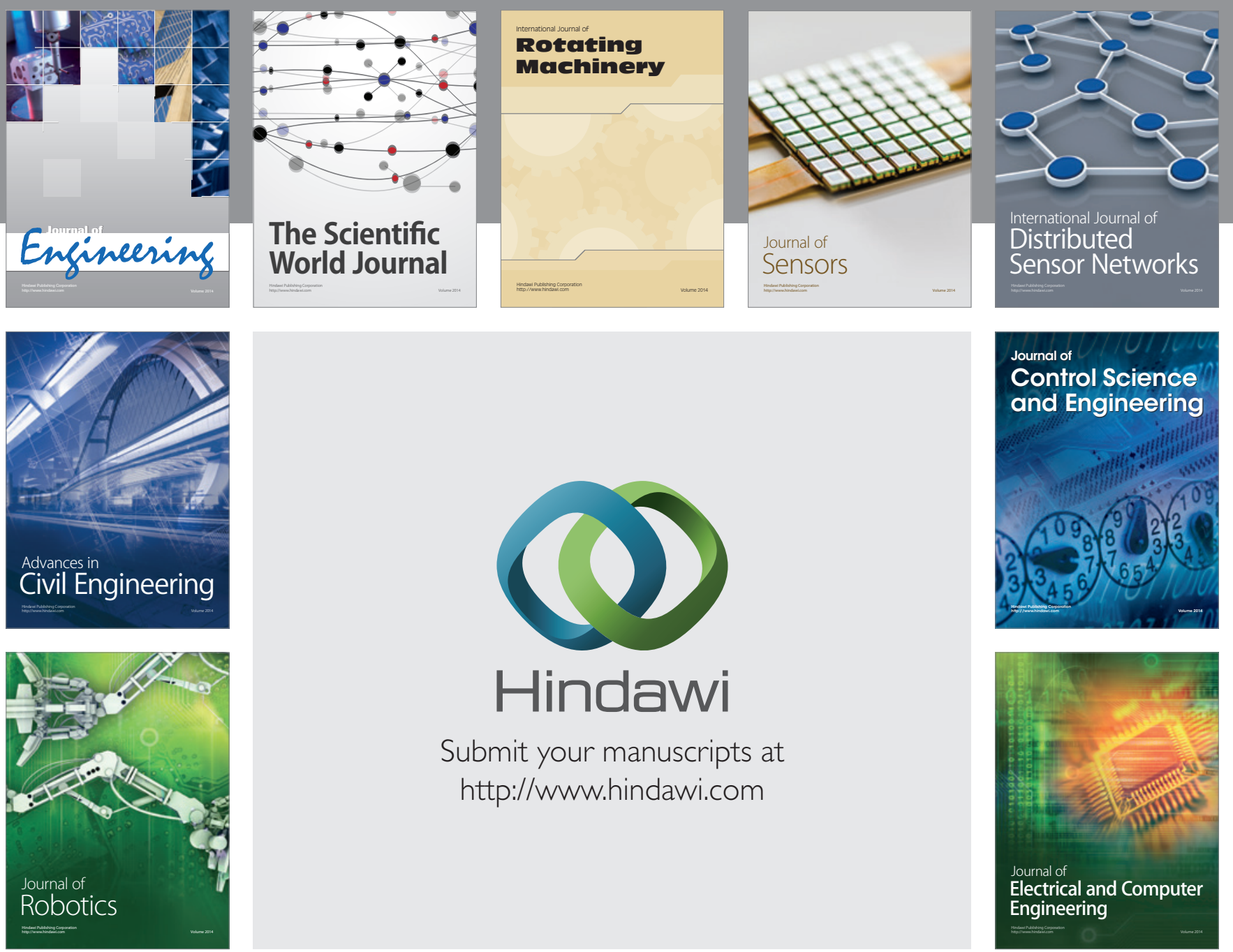

Submit your manuscripts at

http://www.hindawi.com
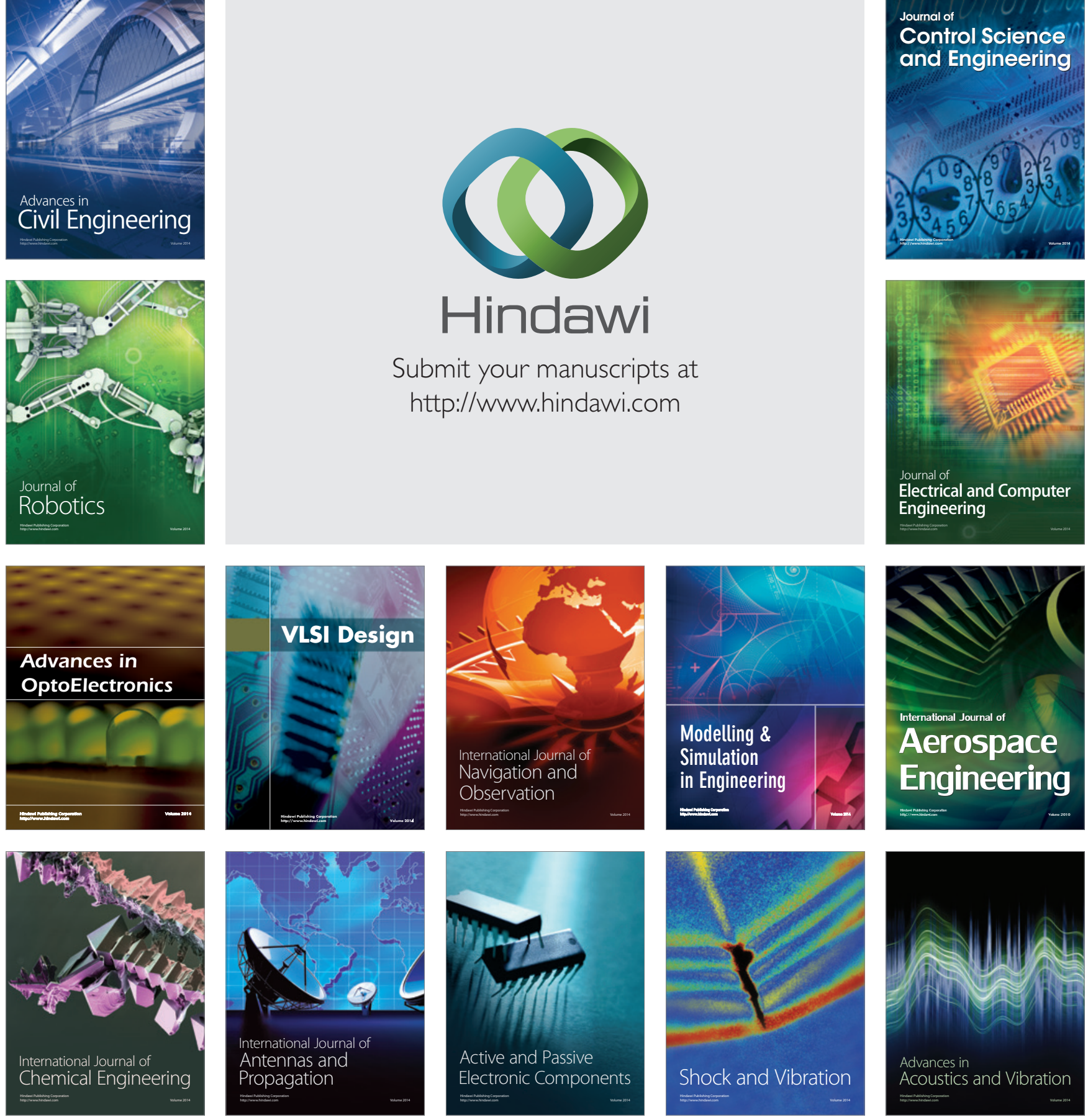